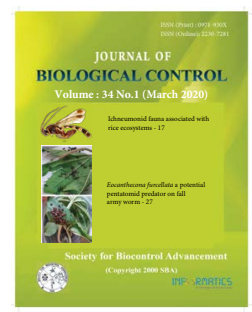

Research Article

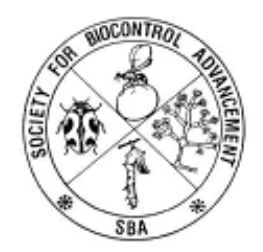

\title{
Biology and potential of pentatomid predator, Eocanthecona furcellata (Wolff) (Hemiptera: Pentatomidae) on fall armyworm, Spodoptera frugiperda (Smith)
}

\author{
A. SRAVIKA ${ }^{2}$, A. N. SHYLESHA ${ }^{1 *}$, K. S. JAGADEESH ${ }^{2}$, T. M. SHIVALINGASWAMY ${ }^{3}$, N. NAGARAJU ${ }^{4}$ and M. S. \\ SHESHSHAYEE ${ }^{5}$ \\ ${ }^{1}$ Division of Germplasm Conservation and Utilization, ICAR-NBAIR, Hebbal, Bengaluru - 560024, Karnataka, India \\ ${ }^{2}$ Department of Entomology, UAS, Bengaluru - 560065, Karnataka, India \\ ${ }^{3}$ Resource Management in Plant Protection, ICAR-NBAIR, Hebbal, Bengaluru - 560024, Karnataka, India \\ ${ }^{4}$ Department of Plant Pathology, UAS, Bengaluru - 560065, Karnataka, India \\ ${ }^{5}$ Department of Crop Physiology, UAS, Bengaluru - 560065, Karnataka, India \\ *Corresponding author E-mail: anshylesha@gmail.com: sravikaachanta@gmail.com
}

\begin{abstract}
Studies on the biology and feeding potential of Eocanthecona furcellata (Wolff) on Spodoptera frugiperda (Smith) were carried out at NBAIR, Bengaluru. Experimental results revealed that the total developmental period from egg to adult for male and female were $27.92 \pm 2.87$ and $39.62 \pm 3.28 \mathrm{~d}$, respectively. The life cycle of male and female passed through first, second, third, fourth and fifth nymphal instars (male: $2.42 \pm 0.51 \mathrm{~d}, 3.25 \pm 0.45 \mathrm{~d}, 3.25 \pm 0.45 \mathrm{~d}, 4.00 \pm 0.60 \mathrm{~d}, 4.42 \pm 0.51 \mathrm{~d}$ ) and (female: $2.54 \pm 0.52 \mathrm{~d}, 3.46 \pm 0.52 \mathrm{~d}, 4.00 \pm 0.71 \mathrm{~d}, 4.38 \pm 0.65$ d, $5.08 \pm 0.49 \mathrm{~d}$ ), respectively. Total nymphal period is about $17.83 \pm 1.34 \mathrm{~d}$ for male and $19.46 \pm 1.20$ days for female, respectively. Adult longevity of male is lower $(10.25 \pm 2.96 \mathrm{~d})$ compared to that of female $(20.15 \pm 3.39 \mathrm{~d})$. The premating period and mating period of adult $E$. furcellata was $2.33 \pm 0.50$ days and $6.44 \pm 2.24 \mathrm{hrs}$, respectively. The pre-oviposition period, oviposition period of adult female was $2.89 \pm 0.60$ and $11.22 \pm 1.72$ days, respectively. The average number of eggs laid by the female was $209.29 \pm 28.11$ in a single mated system. Egg incubation period was about $5.42 \pm 0.51$ days. The predation rates of second, third, fourth, fifth instar nymphs, adult female and male on $2^{\text {nd, }} 4^{\text {th }}, 6^{\text {th }}$ instar prey of $E$. furcellata were $(16 \pm 0.95,27 \pm 4.06,55 \pm 4.67,68 \pm 5.41,126 \pm 4.76,97 \pm 2.85),(7 \pm 1.34,24 \pm 2.77,40 \pm 3.3945 \pm 0.71,88 \pm 1.37$, $51 \pm 1.60)$ and $(4 \pm 0.82,9 \pm 1.64,21 \pm 2.81,38 \pm 1.03,69 \pm 1.32,36 \pm 2.73)$, respectively.
\end{abstract}

KEY WORDS: Biology, developmental period, Eocanthecona furcellata, predatory potential, Spodoptera frugiperda

(Article chronicle: Received: 16-01-2020; Revised: 12-02-2020; Accepted: 25-02-2020)

\section{INTRODUCTION}

The invasive fall armyworm, Spodoptera frugiperda (Smith) was reported in India recently and is spreading fast in the subcontinent. Eocanthecona furcellata (Wolff) (Hemiptera: Pentatomidae) is a potential generalist predator on lepidopteran, coleopteran and heteropteran insects. It has been identified as an effective biological control agent against various lepidopteran pests. In India E. furcellata had been an important predator on several important caterpillar pests, such as larvae of Earias sp. (Pant, 1960), Spodoptera litura (F.) on daincha (Cherian and Brahmachari, 1941), Eutectona machaeralis (Walker), Hyblaea puera (Cramer), Plecoptera reflexa (G.), S. litura (F.) (Ahmad et al., 1996), rice leaf folder, Cnaphalocrocis medinalis Guenee (Kumar and Singh, 2007), Helicoverpa armigera Hubner, Spilarctia obliqua (W.) and Trichoplusia $n i$ (Hubner) on sunflower (Basappa, 2011) and Maruca vitrata Geyer on pigeonpea (Nebapure and Agnihotri, 2011). It can be easily reared on laboratory hosts, Galleria melonella and Corcyra cephalonica. The biology and predatory potential of E. furcellata has been done on several lepidopteran pests but there is no report on the $S$. frugiperda. Hence, this study is aimed to understand the biological parameters and predatory potential of $E$. furcellata on emerging pest, $S$. frugiperda.

\section{MATERIALS AND METHODS}

\section{Rearing of Spodoptera frugiperda (Smith)}

The rearing of Eocanthecona furcellata and experiments regarding the biology and predatory potential were conducted in the laboratory, National Bureau of Agricultural Insect Resources, in the year 2018-2019. The culture of Spodoptera frugiperda was maintained at $26 \pm 2{ }^{\circ} \mathrm{C}$ and $60 \% \mathrm{RH}$. The first and second instar larvae of S. frugiperda were reared on the castor and maize leaves. For stock culture the $3^{\text {rd }}$ instar larvae of $S$. frugiperda were transferred to the individual vials $(4 \times 3 \mathrm{~cm})$ containing cut pieces of 5 days old sun-dried potatoes to avoid cannibalism and vials were plugged with non-absorbent cotton (Plate 2). The larvae for experimental 
purpose were drawn from the culture that reared on the castor and maize leaves.

\section{Rearing of Eocanthecona furcellata (Wolff)}

Adult bugs of $E$. furcellata were collected from University of Agricultural Sciences, Bangalore and farmer fields. For rearing of E. furcellata, (Plate 1) the temperature and relative humidity were maintained as $26^{\circ} \pm 2^{\circ} \mathrm{C}$ and 65 \pm 5 per cent, respectively. The bugs were kept in plastic jars $(30 \times 25 \mathrm{~cm})$ along with bouquet of castor leaves for egg laying and nutrition. Jar was lined with blotting paper and covered with muslin cloth for aeration. Eggs deposited by female bugs on the leaves were separated and kept in small breeding dishes $(5 \times 5 \mathrm{~cm})$ with sieve cap or mesh. Immediately after hatching the first instar nymphs were provided with the moist cotton ball as the first instar nymphs are not predaceous. Later nymphal instars of $E$. furcellata were provided with larvae of Spodoptera frugiperda as they are predatory in nature. Nymphs from third instar were kept in groups of 20 numbers in plastic jars $(15 \times 10 \mathrm{~cm})$ with $S$. frugiperda larvae along with castor leaves and folded paper sheets to avoid cannibalism between nymphs and S. frugiperda larvae.

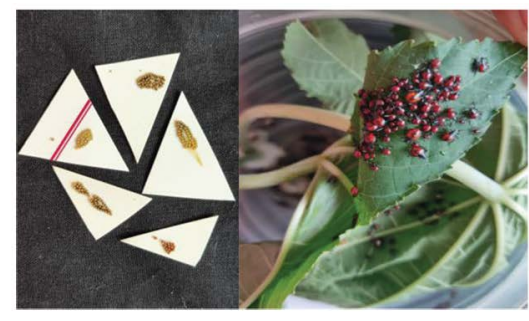

Plate 1a

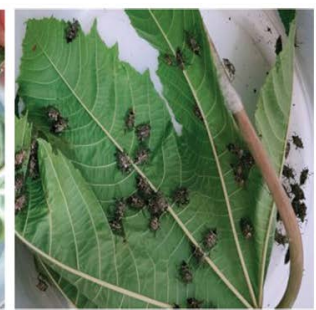

Plate 1c
Plate 1. Mass rearing of Eocanthecona furcellata (a) Egg clutches (b) Nymphal instars (c) Adults of E. furcellata

For biology studies, second instar nymphs $(\mathrm{n}=30)$ were separated in individual plastic jars $(5 \times 5 \mathrm{~cm})$ till the completion of total life cycle. The data of male and females were separated to analyse the mean and SE values. In order to determine the feeding potential of E. furcellata on $S$. frugiperda, one nymph of each predatory bug instar (i.e., II, III, IV and V) were kept in breeding dishes along with twenty S. frugiperda larvae (II, IV and VI instar). The number of consumed larvae was recorded daily and fresh larvae were provided for further feeding. Predation of each nymphal instar was recorded. Similarly, the adults of predatory bug were kept in different vials along with prey, S. frugiperda larvae (II, IV and VI instar). Predation of S. frugiperda was recorded for total adult longevity period of the predatory bug, E. furcellata. Each experiment was replicated thrice (Plate 3).

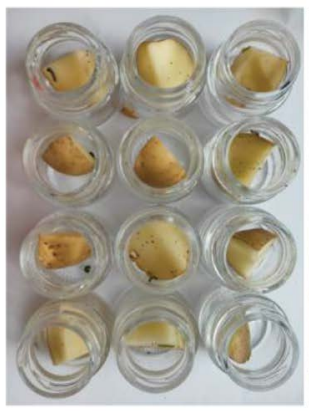

Plate 2

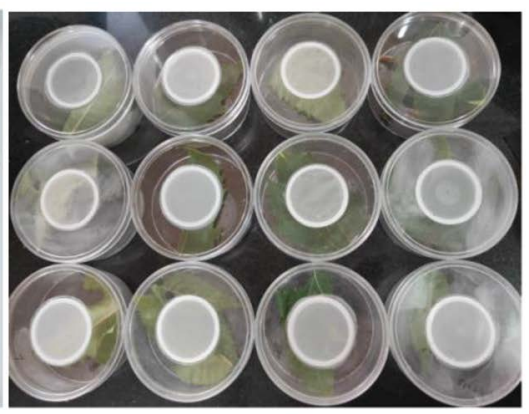

Plate. 3
Plate 2. Rearing of Spodoptera frugiperda for stock culture on potatoes

Plate 3. Experimental set up to determine the predatory otential of Eocanthecona furcellata on $S$. frugiperda

\section{RESULTS AND DISCUSSION}

Experimental results revealed that the total developmental period from the egg to adult for male and female was $27.92 \pm 2.87 \mathrm{~d}$ and $39.62 \pm 3.28 \mathrm{~d}$ respectively. The life cycle of male and female passed through first, second, third, fourth and fifth nymphal instars (male: $2.42 \pm 0.51 \mathrm{~d}$, $3.25 \pm 0.45 \mathrm{~d}, 3.25 \pm 0.45 \mathrm{~d}, 4.00 \pm 0.60 \mathrm{~d}, 4.42 \pm 0.51 \mathrm{~d})$ and (female: $2.54 \pm 0.52 \mathrm{~d}, 3.46 \pm 0.52 \mathrm{~d}, 4.00 \pm 0.71 \mathrm{~d}, 4.38 \pm 0.65$ d, $5.08 \pm 0.49 \mathrm{~d}$ ), respectively. Total nymphal period is about $17.83 \pm 1.34 \mathrm{~d}$ for male and $19.46 \pm 1.20$ days for female, respectively (Table. 1). Adult longevity of male is lower $10.25 \pm 2.96 \mathrm{~d}$ compared to that of female $20.15 \pm 3.39 \mathrm{~d}$. Female bugs were bigger and had more longevity compared to male bugs. The premating period and mating period of adult Eocanthecona furcellata is $2.33 \pm 0.50$ days and $6.44 \pm 2.24 \mathrm{hrs}$, respectively. The pre-oviposition period, oviposition period of adult female $2.89 \pm 0.60$ and $11.22 \pm 1.72$ days, respectively. The average number of eggs laid by the female was $209.29 \pm 28.11$ in a single mated system. The egg incubation period is about $5.42 \pm 0.51$ days. The total number

Table 1. Biology of the predatory bug, Eocanthecona furcellata on Spodoptera frugiperda under laboratory conditions

\begin{tabular}{|c|c|c|}
\hline \multirow{2}{*}{ Biological parameters } & \multicolumn{2}{|c|}{ Duration in days (Mean \pm SE) } \\
\cline { 2 - 3 } & Male & Female \\
\hline First instar & $2.42 \pm 0.51$ & $2.54 \pm 0.52$ \\
\hline Second instar & $3.25 \pm 0.45$ & $3.46 \pm 0.52$ \\
\hline Third instar & $3.75 \pm 0.45$ & $4.00 \pm 0.71$ \\
\hline Fourth instar & $4.00 \pm 0.60$ & $4.38 \pm 0.65$ \\
\hline Fifth instar & $4.42 \pm 0.51$ & $5.08 \pm 0.49$ \\
\hline Total nymphal period & $17.83 \pm 1.34$ & $19.46 \pm 1.20$ \\
\hline $\begin{array}{c}\text { Total development } \\
\text { period (Egg- Adult) }\end{array}$ & $23.25 \pm 1.85$ & $24.88 \pm 1.71$ \\
\hline Adult longevity & $10.25 \pm 2.96$ & $20.15 \pm 3.39$ \\
\hline
\end{tabular}


Biology and potential of pentatomid predator, Eocanthecona furcellata on fall armyworm

Table 2. Reproductive parameters of the predatory bug, Eocanthecona furcellata on Spodoptera frugiperda under laboratory conditions

\begin{tabular}{|c|c|}
\hline Particulars & $($ Mean \pm SE) \\
\hline Pre mating period (Days) & $2.33 \pm 0.50$ \\
\hline Mating period (Hrs) & $6.44 \pm 2.24$ \\
\hline Pre-oviposition period (Days) & $2.89 \pm 0.60$ \\
\hline Oviposition period (Days) & $11.22 \pm 1.72$ \\
\hline Fecundity / female (Nos) & $209.29 \pm 28.11$ \\
\hline Egg incubation period (Days) & $5.42 \pm 0.51$ \\
\hline No of eggs/clutch (Nos) & $40.69 \pm 16.97$ \\
\hline No of egg clutches/female (Nos) & $3.78 \pm 0.44$ \\
\hline
\end{tabular}

of eggs/clutch/female and number of egg clutches/female is $40.69 \pm 16.97$ and $3.78 \pm 0.44$, respectively (Table 2 ).

The results in the present study are in variation with the results of Vanitha et al. (2018) who reported that the incubation period of E. furcellata lasted for 7 days and five nymphal instars being completed in 15-19 days and cannibalism was not recorded. In the present study cannibalism was observed in $3^{\text {rd, }} 4^{\text {th }}, 5^{\text {th }}$ and adults of $E$. furcellata. Mean fecundity was 314 eggs on greater wax moth, Galleria melonella. The incubation period, nymphal duration and total developmental period from egg to adult on Corcyra cephalonica were $8.0 \pm 0.45 \mathrm{~d}, 16.0 \pm 3.24$ and $22.0 \pm 4.20 \mathrm{~d}$, respectively. Pre-oviposition, oviposition and longevity of male and female stink bug were $3.20 \pm 0.38$, $17.60 \pm 1.86,42.40 \pm 1.94,37.00 \pm 3.18 \mathrm{~d}$ respectively (Lenin et al., 2016). Siddaiah et al. (2015) analysed the biology of E. furcellata on vapourer tussock moth larvae showed that the total number of eggs of the predatory stink bug was $44 \pm 8$ days, incubation period $6 \pm 1.05$ days and the life cycle passed through five nymphal instars with a total nymphal period of about $16 \pm 0.64$ days. Male and female longevity were $12 \pm 1.05$ days and $14 \pm 1.09$ days, respectively and total longevity period for male and female lasted $32 \pm 0.19$ and $36 \pm 1.90$ days, respectively. Yi et al. (2000) reported average number of eggs laid by female was 371 and the total life cycle from egg to adult was 24-36 days.

The predation rates of second, third, fourth, fifth nymphal instars on $2^{\text {nd, }} 4^{\text {th }}, 6^{\text {th }}$ instar prey, Spodoptera frugiperda were $(16 \pm 0.95,27 \pm 4.06,55 \pm 4.67,68 \pm 5.41),(7 \pm 1.34,24 \pm 2.77$, $40 \pm 3.3945 \pm 0.71)$ and $(4 \pm 0.82,9 \pm 1.64,21 \pm 2.81,38 \pm 1.03)$ respectively. By comparison, the predation rates of the adult female on $2^{\text {nd }} 4^{\text {th }}, 6^{\text {th }}$ instar prey, S. frugiperda were $126 \pm 4.76$, $88 \pm 1.37,69 \pm 1.32$ respectively. These values were higher than the corresponding male predation rates, $97 \pm 2.85,51 \pm 1.60$ and $36 \pm 2.73$ respectively (Table 3 ). The predation rate of $E$. furcellata suggests that females require more prey than males in order to prepare for egg production and longevity in the adult stage. These results are in variation with the results of Pillai et al. (2013) who reported that there is a significant difference in predation of different instars of E. furcellata which attacked different instars of Maruca vitrata. The trend of predation gradually increased from the $2^{\text {nd }}$ instar to $5^{\text {th }}$ instar nymphs. The per cent predation was $7.60,17.20,35.60$, $43.60,56.40$ and 50.33 by $2^{\text {nd }}, 3^{\text {rd }}, 4^{\text {th }}$ and $5^{\text {th }}$ instar nymph, female and male adults respectively (Nebupare et al., 2011). The predation rates of female N2-N5 nymphs, and adults on Plutella xylostella were 13.5, 8.1, 60.6 and 670.0 larvae, respectively. The present study results are in agreement with the predation rates of the female N2-N3, N4, and N5 nymphs fed on S. litura were 7.6, 19.3, and 57.1 larvae (Tuan et al., 2016). These values are much lower than the values of present study.

Preliminary studies on biology and predatory potential of $E$. furcellata suggests that it has good predatory potential on $S$. frugiperda. The augmentative studies of the predatory bug, E. furcellata in field against $S$. frugiperda should be further explored and could be promoted for the release under pest outbreaks situations.

\section{ACKNOWLEDGEMENTS}

Laboratory facilities provided by ICAR-National Bureau of Agricultural Insect Resources and Department of Agricultural Entomology, UAS, Bengaluru are sincerely acknowledged. Senior Research Fellowship provided by ICAR is gratefully acknowledged.

Table 3. Feeding potential of the predatory bug, Eocanthecona furcellata on Spodoptera frugiperda

\begin{tabular}{|c|c|c|c|c|c|c|}
\hline \multirow{2}{*}{ Stages of host, S. frugiperda } & \multicolumn{5}{|c|}{ Stages of predator, E. furcellata (Mean \pm SE) } \\
\cline { 2 - 7 } & Second instar & Third instar & Fourth instar & Fifth instar & Adult female & Adult male \\
\hline Second instar (no.) & $16 \pm 0.95$ & $27 \pm 4.06$ & $55 \pm 4.67$ & $68 \pm 5.41$ & $126 \pm 4.76$ & $97 \pm 2.85$ \\
\hline Fourth instar (no.) & $7 \pm 1.34$ & $24 \pm 2.77$ & $40 \pm 3.39$ & $45 \pm 0.71$ & $88 \pm 1.37$ & $51 \pm 1.60$ \\
\hline Sixth instar (no.) & $4 \pm 0.82$ & $9 \pm 1.64$ & $21 \pm 2.81$ & $38 \pm 1.03$ & $69 \pm 1.32$ & $36 \pm 2.73$ \\
\hline
\end{tabular}




\section{REFERENCES}

Ahmad M, Singh AP, Sharma S, Mishra RK and Ahmad MJ. 1996. Potential estimation of predatory bug, Canthecona furcellata Wolff. against poplar defoliator, Clostera cupreata. Ann Forestry 4(2): 133-138.

Basappa H. 2011. Biodiversity of biocontrol agents in sunflower ecosystem. J Biol Control 25(3): 182-187.

Cherian MC and Brahmachari K. 1941. Notes on the three predatory hemipterans from south India. Indian $J$ Entomol. 3: 115-119.

Kumar S and Singh SV. 2007, Longevity fecundity and sex ratio of Canthecona furcellata on lepidopterous insect pests. Ann Plant Prot Sci. 15(7): 235-281.

Lenin SEA and Rajan SJ. 2016. Biology of predatory bug Eocanthecona furcellata Wolff (Hemiptera: Pentatomidae) on Corcyra cephalonica. J Entomol Zool Stud. 4(3): 338-34.

Nebapure SM and Agnihotri M. 2011. Canthecona furcellata: A predator of Maruca vitrata. Anna Plant Prot Sci. 19: 451-508.

Pant CP. 1960. Some aspects of bionomics of Eariasw spp. at Kanpur. Agra University. J Res Sci. 9: 31-40.
Pillai AK and Agnihotri M. 2013. Biology and predatory potential of Eocanthecona furcellata (Wolff.) on Maruca vitrata Geyer. Madras J Agric Sci. 100: 193-195.

Siddaiah AA and Devi AR. 2015. Biology of a predatory bug Eocanthecona furcellata Wolff (Hemiptera: Pentatomidae) on Vapourer tussock moth larvae: a major pest of tasar silkworm food plants. Int J Indust Entomol. 30(1): 26-30. https://doi.org/10.7852/ijie.2015.30.1.26

Tuan SJ, Yeh CC, Atlihan R and Chi H. 2016. Linking life table and predation rate for biological control: A comparative study of Eocanthecona furcellata (Hemiptera: Pentatomidae) fed on Spodoptera litura (Lepidoptera: Noctuidae) and Plutella xylostella (Lepidoptera: Plutellidae). J Econ Entomol. 109(1): 13-24. https://doi. org/10.1093/jee/tov265

Vanitha K, Raviprasad TN and Shwetha V. 2018. Life cycle of Eocanthecona furcellata Wolff. (Hemiptera: Pentatomidae) a predatory bug in cashew plantations, upon rearing on wax moth larvae. $J$ Entomol Zool Stud. 6(2): 3007-3010.

Yi NN and Kyi W. 2000. Biological Control Research Center, Mandalay Division, Singaing Township, Paleik, Myanmar. Proceedings of the Annual Research Conference (Agricultural Sciences), Yangon, Myanmar, pp.58-73. 